\title{
Exploring the Diet and Physical Activity Behaviours of Adolescents Living in India and sub-Saharan Africa: A Qualitative Evidence Synthesis
}

Polly Hardy-Johnson ${ }^{1}$ and Preeti Dhuria ${ }^{1}$, Sofia Strommer ${ }^{1}$, Susie Weller ${ }^{2}$, Mary Barker ${ }^{1}$, Caroline Fall ${ }^{1}$, on behalf of the TALENT collaboration

\section{Affiliations:}

${ }^{1}$ MRC Lifecourse Epidemiology Unit, University of Southampton, Southampton University Hospital, UK

${ }^{2}$ Clinical Ethics and Law (CELS), Centre for Cancer Immunology, University of Southampton, Southampton University Hospital, UK

Corresponding author: Polly Hardy-Johnson, MRC Lifecourse Epidemiology Unit, University of Southampton, Southampton General Hospital, Tremona Road, Southampton SO166YD, UK; phj@mrc.soton.ac.uk

*Joint first authors

Short Title: Adolescent diet and physical activity in LMICs: A Qualitative Evidence Synthesis

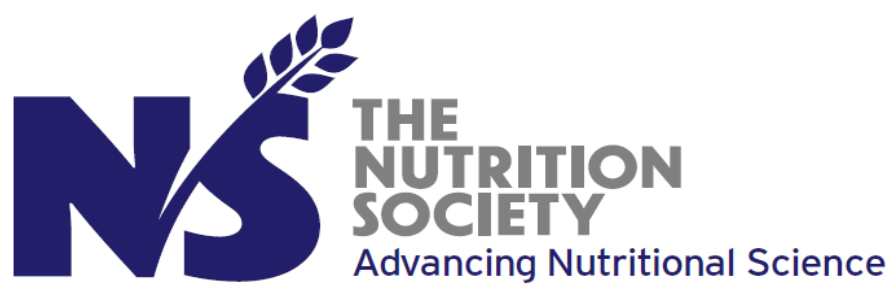

This is an Accepted Manuscript for Public Health Nutrition as part of the Cambridge Coronavirus Collection. This peer-reviewed article has been accepted for publication but not yet copyedited or typeset, and so may be subject to change during the production process. The article is considered published and may be cited using its DOI $10.1017 / \mathrm{S} 1368980021002408$ Public Health Nutrition is published by Cambridge University Press on behalf of The Nutrition Society 


\section{Acknowledgements:}

The TALENT collaboration comprises:

Laurence Adonis-Koffy, Yopougon University Hospital Faculty of Medical Sciences UFHB de Cocody Abidjan Ivory Coast; Ulka Banavali, Regional Center for Adolescent Health and Nutrition, BKL Walawalkar Rural Medical College, Chiplun, India; Edna Bosire, University of the Witwatersrand, Johannesburg, South Africa; Harsha Chopra, Centre for the Study of Social Change, Mumbai, India; Meera Gandhi, Centre for the Study of Social Change, Mumbai, India; Abraham Haileamlak, College of Public Health and Medical Sciences, Jimma University, Jimma, Ethiopia; Ramatoulie Janha, MRC Keneba, MRC Unit The Gambia, MRC Keneba; Landing Jarjou, MRC Unit The Gambia; Julie Jesson, Inserm U1027, University of Toulouse, Paul Sabatier, France; Shama Joseph, Epidemiology Research Unit, CSI Holdsworth Memorial Hospital, Mysore, India; Sarah H Kehoe, MRC Lifecourse Epidemiology Unit, University of Southampton, Southampton General Hospital, UK; Kejal Joshi Reddy, Unit, KEM Hospital, Pune, India; Elizabeth Kimani-Murage, African Population and Health Research Center (APHRC), Nairobi, Kenya; Egnon Kouakou, PAC-CI, Abidjan, Ivory Coast; GV Krishnaveni, Epidemiology Research Unit, CSI Holdsworth Memorial Hospital, Mysore, India; Kalyanaraman Kumaran, MRC Lifecourse Epidemiology Unit, University of Southampton and Head, UK and Epidemiology Research Unit, CSI Holdsworth Memorial Hospital, Mysore, India; Valeriane Leroy, Inserm U1027, University of Toulouse, Paul Sabatier, France; Mubarek Abera Mengistie, Jimma University, Ethiopia; Sophie Moore, Kings College London, London, UK; Shane Norris, Developmental Pathways Research Unit, University of the Witwatersrand, Johannesburg, South Africa; Suvarna Patil, Regional Center for Adolescent Health and Nutrition, BKL Walawalkar Rural Medical College, Chiplun, India; Sirazul Ameen Sahariah, Centre for the Study of Social Change, Mumbai, India; Kate Ward, MRC Lifecourse Epidemiology Unit, University of Southampton, UK; Stephanie Wrottesley, University of the Witwatersrand, Johannesburg, South Africa; Chittaranjan Yajnik, Diabetes Research Unit, KEM Hospital, Pune, India; Pallavi Yajnik, Diabetes Research Unit, KEM Hospital, Pune, India. 
Financial support: This study was funded by a Global Challenges Research Fund/ Medical Research Council pump priming grant (grant number: MC_PC_MR/R018545/1) and a University of Southampton Global Challenges Research Fund Strategic Development grant. The funding agency was not involved in the study design, data analysis, or writing of this article.

\section{Conflict of Interest: None}

Authorship: PHJ and PD designed the search strategy, ran the searches, sifted through the results, and conducted the synthesis, and drafted the manuscript. CHDF, MEB, SW and SS contributed to the manuscript.

Ethics statement: This study was conducted according to the guidelines laid down in the Declaration of Helsinki and all procedures involving research study participants were approved by the University of Southampton ethics committee. Written informed consent was obtained from all participants. 
Accepted manuscript

\begin{abstract}
Objective: To carry out a qualitative evidence synthesis to explore what influences the diet and physical activity of adolescents living in five countries that constitute the Transforming Adolescent Lives through Nutrition (TALENT) consortium (Cote D'Ivoire, Ethiopia, India, South Africa and The Gambia).
\end{abstract}

Design: A search of electronic databases was conducted for qualitative articles published between 2000 and 2019.

Participants: Studies that explore influences on the diets and physical activity habits of adolescents aged 10-19 years.

Results: Of the twelve included studies, none were identified from The Gambia or Cote D'Ivoire. The existing qualitative literature focussed on three major areas in relation to adolescent diet and physical activity: 1) the influence of body image and self-esteem;2) social and environmental influences; and 3) poverty. The limited existing literature focusses heavily on girls' experiences particularly in relation to body image and dysfunctional eating practices.

Conclusions: In-depth research exploring adolescents' perceptions of diet and physical activity is needed to better understand how both boys and girls, at different stages of adolescence, perceive health, diet and physical activity. More research with young people is required especially in countries where little exists to cover a wider range of issues that play a role in diet and physical activity.

Keywords: Adolescent; Health; LMICs; Qualitative; Review 
Accepted manuscript

\section{Introduction}

Adolescence (10-19 years) is a period of rapid growth and development which marks the transition from childhood to adulthood. Adolescent malnutrition, including both undernutrition and obesity, in low-and-middle-income countries (LMICs) is a major public health concern. Nutritional requirements increase during adolescence to enable the growth, sexual maturation and brain re-modelling necessary. $(1,2)$ Diet and physical activity habits adopted in adolescence can influence lifelong health behaviour. (1) Adolescent nutrition research has been neglected in LMICs where the dual burden of malnutrition is common. Malnutrition including anaemia and stunting remain commonplace while at the same time, urbanisation and economic and societal transitions are contributing to increasing obesity leading to later life non-communicable chronic diseases (NCDs).(3) Optimising nutrition during adolescence has the potential to both improve the health of adolescents themselves now and in future, and that of the next generation. $(1,4,5)$

Almost one-quarter of the world's population comprises adolescents and young adults (10-24 years), with more than $80 \%$ living in LMICs.(4) Adolescent diet and physical activity behaviours are driven by a complex interaction of factors at the individual, familial, community and environmental levels. During this time, an individual's sphere of influence expands from their immediate family to include their peers, the community, culture, education, the media and the economy. (6) In addition, many LMICs are undergoing rapid urbanisation which is associated with adolescents' engaging in obesogenic behaviours due to exposure to cheap calorie dense foods and sedentary lifestyles. (3)

Although it is important to understand the impact of these transitions on young people's lives (7) nutrition research with children and young people in LMICs is in its infancy. Qualitative methodologies provide an opportunity to gain insights into the lives, experiences and perspectives of adolescents living in these rapidly transitioning settings. Qualitative methods enable the complexities of everyday life to be captured and documented, providing new insights into young people's experiences and how these shift as they move from childhood, through adolescence and into young adulthood. (8) Youth-centred research views adolescents as experts of their own lives and enables the collection of rich, novel research findings whereby context is taken into account. (9) Given the complex nature of adolescence and the influences on their diet and physical activity behaviours, qualitative research methodologies represent a valuable method for generating insights into the key drivers behind these 
behaviours. Synthesising qualitative evidence allows us to aggregate findings that explore adolescent diet and physical activity behaviours across multiple contexts. (10)

Established in 2018, Transforming Adolescent Lives through Nutrition (TALENT) is a consortium of researchers from the Europe (France, UK), India (Dervan, Mumbai, Mysore, Pune) and sub-Saharan Africa (Abidjan, Cote D'Ivoire; Jimma, Ethiopia; Kiang West, The Gambia; Soweto, South Africa) at different stages of economic and societal transition, who share a special interest in adolescent nutrition. This paper is part of a special issue (see Barker et al., this issue) focused on addressing the evidence gap in adolescent nutrition research within these settings.

Aim of this review.

To review the qualitative literature exploring influences on diet and physical activity behaviours among adolescents across Côte d'Ivoire, Ethiopia, India, South Africa, and The Gambia.

Specifically, this review aims to synthesise the qualitative literature exploring:

(a) Adolescents' (10-19 years) perceptions of diet and physical activity behaviours;

(b) Body image and satisfaction/dissatisfaction in adolescents and how these may influence their diet and physical activity behaviours;

(c) Perceptions of and attitudes towards healthy eating and physical activity and the barriers and/or facilitators to these behaviours in adolescents living in TALENT sites (Côte d'Ivoire, Ethiopia, India, South Africa, and The Gambia).

\section{Methods}

\section{Search Strategy and Selection Criteria}

Search terms were defined by scanning key words from relevant papers in an initial scoping search. Keywords were divided into categories using a modified version of the PICO formula. Terms were therefore divided into population, context (location and study design, separately) and outcome. Comprehensive literature searches were conducted in January 2019 by two researchers (PD and PHJ), in two stages: 1) scanning of titles and abstracts and 2) full text reviewing of studies against the exclusion/inclusion criteria. Searches identified all available studies published between January 2000 and January 2019. The search strategy was developed based on the PICO method (11) and search terms through meetings amongst the 
TALENT team and keywords identified from a scoping review of potentially relevant articles (see Table 1). The following limits were added to all searches: 1) studies conducted in India, South Africa, Ethiopia, Cote D'Ivoire, and The Gambia and 2) studies that have been published between 2000 and 2019 in English.

Insert Table 1. Search Terms used to identify relevant studies exploring the influences on adolescent diet and physical activity.

Searches were conducted using five key electronic databases: Medline, Web of Science, EMBASE, CINAHL, and PsychINFO. To supplement the electronic searches, a search of the online publication list of a collaboration, Young Lives, (12) a longitudinal, global study into children and youth was conducted. The reference lists of all included studies were also scanned to identify any potentially relevant studies. Search results were imported into EndNote (bibliographic software) where, following the PRISMA (13) chart (see figure 1), two researchers (PD and PHJ) independently screened potentially relevant titles and abstracts. Following this, the same researchers independently screened full-text articles against the inclusion/exclusion criteria:

\section{Inclusion Criteria}

Studies were included in this review if they: 1) explored adolescents' perspectives and/or experiences of diet and/or physical activity behaviours; 2) were conducted in India, South Africa, Ethiopia, Cote D'Ivoire, or The Gambia; 3) collected data from boys and/or girls aged 10-19 years; 4) were published between 2000 and January 2019, in English; 5) used a qualitative study design including: observations, face-to-face interviews, or focus group discussions (FGDs); and 6) published in peer-reviewed journals.

Studies were excluded from this review if they: 1) did not use qualitative methods; 2) did not collect data from adolescents aged 10-19 years old; 3) collected and analysed data from parents, teachers, or other stakeholders; and 4) were not available in English.

Once included studies had been identified, data was extracted from each included study on aims, participant details (age, sample size), design (method of data collection), outcomes related to diet and physical activity and conclusions. The standardized Critical Appraisal Skills Programme CASP (14) checklist recommended by the University of York Centre for Reviews (CRD) Guidelines for writing systematic reviews was used to consider the quality of studies being synthesised. (15) The CASP checklist contains 10 items based on the research 
aims, methods used, the role of the researcher, data analysis method, the clarity of the findings and value of the research (http://www.casp-uk.net/\#!casp-tools-checklists/c18f8). The quality assessment was undertaken independently by two reviewers (PD, PHJ), with disagreements resolved through discussion. The outcome of each CASP item is reported for each included study in Appendix A.

\section{Qualitative synthesis}

This qualitative evidence synthesis report is written using the ENTREQ statement guidelines to enhance transparency. (16) The challenges associated with synthesising qualitative literature are different to those concerning quantitative publications. A qualitative synthesis is similar to qualitative research whereby the findings from other qualitative studies are pooled and synthesised. The findings from the included studies in this review have been pooled, uploaded to the qualitative analysis software NVIVO v12, and thematically analysed based on CRD guidance, (15) following Braun and Clarke's guide (17) to develop an overall synthesis of main findings. (18) PHJ coded the findings of the included papers deductively, focussing on findings related to adolescents' perceptions of health, diet and physical activity behaviours. These codes were reviewed, revised and discussed amongst the research team. Once the coding framework was finalised (see except in Appendix B), codes were merged with other similar codes and eventually categorised under broad headings. These categories were then reviewed, revised, and developed into three broad themes that represented the main areas of research focus in the literature so far.

\section{Results}

\section{Description of included studies}

The searches retrieved 7787 titles and abstracts to be screened, following which, 79 full-text papers were screened (see figure 1). 12 studies (from which 13 papers were produced) were deemed eligible for inclusion in this review (see table 2). It is important to note that the findings of this review are based heavily on studies conducted in just two countries, India and South Africa. Five studies were carried out in South Africa (19-23) of which, there were two in urban settings $(19,20)$, two in rural settings $(21,22)$, and one in which the setting was not reported. (23) All five of these papers recruited girls only. Five studies were carried out in India (24-27) in which the settings were either not reported $(24,27)$ or included participants from both rural and urban settings. $(25,26)$ Three of the five Indian studies collected data 
from both boys and girls, and one recruited girls only. One study presented results from data collected from both girls and boys from urban settings in both South Africa and India. (28) Finally, one study that was conducted in rural Ethiopia with data from both boys and girls included in this review. (29) Of the included studies, data collection methods comprised focus group discussions $(20,22,24-28)$, in-depth duo interviews $(19,21)$, in-depth individual interviews $(23,28)$, community mapping (28), photo voice (28), and case study reports (29).

The quality of the included studies was considered using the CASP checklist and presented in Appendix A. Overall, most studies met the quality criteria outlined in the CASP checklist. Most studies clearly described the aims of the research, used an appropriate methodology to address their aims, and outlined the approach to recruitment and data collection in a manner appropriate to the research issue/questions. Data analysis was clearly described by most studies, with two studies lacking in some clarity and one study giving no detail about analytical methods beyond citing the name of a method. Findings were clearly and sufficiently described in all studies. A key weakness for most the studies was the lack of description regarding the role of the researchers and the relationship between researchers and participants, which was only partially achieved in two studies, and not clearly addressed in the rest of the studies. Ethical issues, such as how the research was explained to participants, and issues around informed consent and confidentiality, were fully and clearly described in only 5 studies, with 7 studies presenting insufficient or unclear information.

\section{Narrative Synthesis}

The qualitative literature reviewed focused on three main themes in relation to adolescent diet and physical activity: 1) The influence of body image and self-esteem; 2) social and environmental influences; and 3) poverty (see figure 2). See Figure two for a visual display of the themes and subthemes. Table 3 depicts the themes that were expressed by adolescents from each research site.

\section{Theme 1: The Influence of Body Image and Self-Esteem on Diet and Physical Activity}

\subsection{Desire to be thin vs 'curvy'}

The impact of body image and self-esteem on the diet of adolescent girls was a major theme, particularly in the most economically transitioned research site, South Africa. There was a clear contrast between girls in the South Africa studies who wanted to be 'curvy' and those who desired a thin body shape. There was a stigma about thinness, as many of those who 
strived for a fuller body shape associated thinness with stress and illness, particularly AIDS. However, there was a distinction made in one of the studies between what girls referred to as 'sick skinny' and 'nice skinny'. (20) In contrast, many girls felt enormous pressure to be thin from external sources, including clothing stores. (20) There was also a perception that thinness was a requirement for being 'popular' at school and for obtaining a boyfriend. (20, 22)

In contrast, in the least economically transitioned research setting Ethiopia, obesity was desirable as it was associated with a person who is living a good life. Weight was rarely mentioned in all but one of the studies conducted in India. (25) The overweight adolescents felt that their healthy weight peers were overly and 'unnecessarily' concerned with 'being skinny'. Although, most of the adolescents in the studies conducted in India did not mention weight, the salience of appearance to adolescents was clear, though this largely focussed on cleanliness, hygiene and clothing. (24)

\subsection{Peers and family influencing body image.}

The motivation to become 'thin' was rarely health related. In the studies from South Africa, the social element of losing weight with friends, and strong desire to avoid teasing and humiliation by peers and family heavily influenced weight ideals. $(19,22)$ Cultural differences in idealised body shapes also contributed to body image concerns among black South African girls. Socialising with white South African girls, who themselves would strive for thinness, increased the perceived pressure for them to do the same. In contrast, girls from the Kinsman (2015) study felt pressured by peers to gain weight because they would be ridiculed for being thin. (22) However, although curves were desirable, girls in this study indicated that muscle definition was not. For example, defined arms were associated with household chores which indicated poverty and exposed the girls to the possibility of further bullying.

\section{$\underline{1.3 \text { Dysfunctional eating practices }}$}

There were multiple types of dysfunctional eating practices reported by girls in the South African studies focussing on body image including skipping meals, smoking to suppress hunger, using diet pills, drinking vinegar, over exercising, and purging which included both vomiting and using laxatives. (23) Peers swapped knowledge of various weight loss methods and encouraged their friends to lose weight. Other adolescents with 'good figures' were seen 
as role models. (23) These dysfunctional eating practices were mostly used to lose weight however, several other motivations were reported. For example, meals were often skipped due to the embarrassment of eating cultural-specific home-cooked lunch in front of peers. (20) Some cultural traditions also lead to girls participating in regular purging. This was often encouraged by parents, some of which would buy laxatives for family members to purge any consumed food which was perceived to contain toxins. (20)

The research exploring the influence of body image and self-esteem on diet was gendered with a focus on adolescent girls. This compares with findings from high income countries, where body dissatisfaction has been found to be more commonly reported amongst girls than boys. (30) In this review, disordered eating practices were only explored among adolescent girls living in the most economically transitioned setting (South Africa). This is also comparable with qualtiative studies finding that peers and a dissatisfaction with body image influence 'crash dieting' behaviours. (31)

\section{Theme 2: Social and Environmental Influences on Diet and Physical Activity}

\subsection{Safety of outside spaces and physical activity}

Across both the South African and Indian literature, adolescents' concerns for their own safety, particularly among girls, were apparent. Fear of violent attacks and sexual exploitation had a negative impact on adolescents' use of outside spaces. This was particularly prominent in the South African literature where many girls reported feeling unsafe in their environment. (28) Indian adolescent girls were often forbidden from leaving their homes. This was due to fears from both adolescents and their parents that girls leaving the home would inevitably be at risk of sexual exploitation, which would 'defame' their families. This restriction was gendered, with boys having complete freedom to use outside spaces. (28) Safety concerns were only highlighted in the settings undergoing economic transition and urbanisation in this review. Perceived safety is often associated with fear of crime in urban settings. (32)

\subsection{Academic pressure versus diet and physical activity}

Pressure to perform well academically was a common theme across the studies, particularly in the Indian studies. Indian adolescents emphasised how academic pressure, busy schedules and the resulting stress were key barriers to engaging in physical activity and eating healthily. Adolescents in Correa's (2017) study were being academically tested every day. Academic pressures took priority over food so much so that some adolescents reported that they forgot 
to eat once they had finished studying. Others reported feeling too 'tensed' about their tests to eat. (26) Age also influenced how much adolescents were encouraged to focus on academic achievement over and above physical fitness. For example, South African adolescents reported that as they got older, they were encouraged to engage in increasing academic study and discouraged from participating in extra-curricular activities, including sports. (21)

\subsection{Eating and doing physical activity with friends and family.}

Most included studies, from all countries, found that adolescents were knowledgeable about nutrition, food hygiene, and understood that home-cooked food was generally healthier than 'outside' food. This was not just due to nutritional content, adolescents reported that 'outside' food maybe be prepared in a way that was unhygienic. It was believed that street vendors might not wash their hands and utensils regularly or 'properly', they might not maintain good levels of personal hygiene, and that they might reuse their cooking oils. $(25,26)$ However, despite this awareness adolescents continued to eat 'outside' junk foods. Both Indian and South African adolescents reported that they ate more junk foods when socialising with their friends. Food was an important part of the adolescents' social worlds whereby friendship groups or pairs would often purchase and eat these foods together. (19) Although adolescents were more likely to eat junk food when in the presence of friends, peers also encouraged each other to engage in physical activity. (21) Peers having a significant influence on adolescent diet and physical activity has been found across the globe, including adolescents living in high income countries. (33)

\section{Theme 3: Poverty, Diet, and Physical Activity}

\subsection{Food (in) security}

One Ethiopian study was eligible for inclusion in this review, which was also the least economically transitioned setting. The main message of which was the complex interaction between poverty and diet. For those adolescents living in the most rural, resource poor settings, being able to satisfy their hunger was key to having a good quality of life. Adolescents distinguished each other as 'rich or poor' by the types of food they ate. Food insecurity was also gendered in Ethiopia, due to restrictions on girls' mobility. For example, adolescents in this study reported that as girls got older, there was an expectation that they helped with domestic chores. Where girls mostly stayed at home and had little financial independence, the adolescent boys were encouraged to work outside of the home in 
agricultural practices or to move to towns to earn money. (29) Reliance on subsistence farming in Ethiopia was clear and many families were living 'hand-to-mouth'. As a result, adolescents valued the rain highly because it was an assurance that crops would grow, and that they and their families could eat. Though food insecurity was much less of a factor in South Africa, there was mention of it and how it influenced the adolescents' diets. For example, adolescents in Sedibe's (2014) study reported that many young people skip breakfast due to lack of available food. (21) In South Africa, groceries were bought monthly. Once these had been consumed, many families would rely on foods they could pick from the fields. During these times, adolescents often would not be able to take a packed lunch to school. Despite this, many preferred not to eat the poor-quality free school food. Girls reported having stomach cramps from eating the free school meals. Instead, they would walk around outside and avoid eating the food.

\subsection{Food safety and hygiene}

Food hygiene was incredibly important to the Indian adolescents, who were concerned about the possible contamination of outside foods. Alongside the rapid economic and nutrition transition in India has seen an increase in outside food vendors and markets. There was a good understanding that unhygienic foods could cause illness and therefore should be avoided, where possible. They were particularly concerned with 'open foods' that were not covered and were exposed to flies. $(25,26)$ Despite this, adolescents were still tempted to buy food from roadside vendors. (26)

\section{$\underline{3.3 \text { Poverty as a barrier and facilitator to physical activity }}$}

Poverty both encouraged participation in and acted as a barrier for adolescent physical activity as was emphasised particularly in the studies conducted in South Africa. Many had no choice but to engage in physical domestic work at home, and others were incentivised to take part in sporting competitions by the prospect of a cash prize. (22) For those adolescents who lived in impoverished areas, sports facilities were either limited or vandalised, and outdoor spaces were deemed unsafe. Opportunities to use outdoor spaces and sports facilities were gendered, with girls limited to poorly funded sports spaces compared to boys. 


\section{Discussion}

Using a qualitative evidence synthesis approach, this paper reviewed and thematically synthesised the available qualitative literature exploring influences on diet and physical activity behaviours among adolescents living in five TALENT countries (India, South Africa, Côte d'Ivoire, Ethiopia and The Gambia). The existing qualitative literature focussed on three major areas in relation to adolescent diet and physical activity: 1) the influences of body image and self-esteem; 2) social and environmental influences; and 3) poverty (see Figure 2). Most studies provided good quality reports of thoughtful and rigorous qualitative work. The main weaknesses inherent in most of the studies comprised not reflecting adequately on the role of the researchers and the relationship between researchers and participants and reporting clearly on key ethical considerations. The small number of studies identified for inclusion in this review supports previous reports that qualitative research remains in its infancy within developmental studies in LMICs and tends to lack credibility with more quantitatively orientated researchers and public policy makers.(38) Although large-scale quantitative methodologies are important and can offer an insight into trends across populations, qualitative research can provide a more in-depth insights into the complex experiences of adolescents living in transitioning societies and how this relates to diet and physical activity.(39)

\section{Implications of body image and self-esteem on diet and physical activity}

The South African studies focussed heavily on adolescent body image its relation to diet and physical activity, and primarily among South African adolescent girls. These studies highlighted a contrast in concerns between adolescents who desired a 'curvy' figure and those who desired to be 'thin'. South Africa is home to a diverse population and previous research has shown that ethnicity may influence these differences in perceptions of the 'ideal' body shape and body dissatisfaction.(36) Previous reviews have indicated white adolescent girls in South Africa were more likely to idealise a 'thin' body image compared to their Black South African peers.(37) Despite this, the studies in this review showed that young Black women engaged more in disordered eating practices including purging.(37) In the findings of the current review, South African girls expressed a desire to 'look good' which for many was associated with thinness. For some, this was due to the belief that boys found thin girls more attractive. Interestingly, body image was not explored among adolescent boys. In Africa, most of the previous research into adolescent body image has focussed on girls. $(36,38)$ This 
may be because dysfunctional eating practices are frequently reported among adolescent girls than boys or because adolescent overweight and obesity are much more common in girls than boys in this setting.(39) There have been studies, however, showing that ethnicity is also associated with differences in BMI, eating attitudes and self-esteem in boys.(40)

\section{Social \& environmental influences on diet and physical activity}

The findings of this review show that academic pressure, perceived safety of outside spaces, and family and friends have influence over adolescent diet and physical activity behaviours. These findings support research from high-income countries and show that, although mothers have a strong influence over what is eaten at home (41), decision making about food is actually very complex, with many factors influencing the choice of family meals including negotiations between all family members.(42) Although similar studies in HICs have highlighted the influence of the family, there are often many more factors associated with food choice, including the increasing importance of peer influence during adolescence. Interactions with peers are complex (43) and this is demonstrated in the findings of the current review in relation to diet. Many of the adolescents in this review felt that their peers influenced their body image, dieting and weight-loss behaviours. In contrast however, they also felt that they influenced the consumption of calorie-dense junk foods.

\section{Poverty, diet and physical activity}

Although there was only one study from Ethiopia, the findings provide a unique insight into the lives of the adolescents living there, and how important their socio-economic status was in determining their diet.(29) Interestingly, although food insecurity was the focus of discussion, body image was still mentioned in this study. Weight was used to distinguish between rich and poor, with obesity being associated with affluence. Many LMICs including, India and many countries within sub-Saharan Africa, are undergoing transitions in diet, nutritional status and life expectancy. $(44,45)$ These transitions from rural subsistence to urban economies are associated with a shift towards a more urbanised diet with increasing availability of calorie-dense junk foods. However, many areas in India and sub-Saharan Africa, including Ethiopia are still in the early stages of transition whereby affordability and availability are key determinants of nutritional status. 


\section{Review Findings in the Context of Nutrition Transition}

The findings of this review are based largely on qualitative studies conducted in South Africa and India, both of which are both rapidly undergoing economic and nutrition transition. In high-income countries, such as the United Kingdom, 'ultra-processed', calorie-dense foods have been one of the main sources of energy consumed since the 1950s. (46) However, these types of foods have only recently been available globally. Urbanisation in both India and South Africa has led to a shift towards a more westernised diet, characterised by 'ultraprocessed', calorie-dense, nutrient poor foods which have a profound impact on the health of these populations. The double burden of malnutrition seen in transitioning setting s presents a serious public health challenge. (47) For example, India is facing an epidemic of NCDs that exists alongside prevalent undernutrition resulting in substantial socioeconomic burden.(45) Along with high rates of undernutrition there has been a significant increase in the prevalence of overweight and obesity in both India and South Africa $(48,49)$. This nutrition transition is reflected in the findings of this review in as far as studies with adolescents in the more transitioned settings focus discussions on both over and underweight (India and South Africa) and in this way differ from the focus on food insecurity in discussions with adolescents from Ethiopia, which is at an earlier stage of transition. The findings from the more transitioned settings in this review indicate that social influences, including peers are key influences on diet and physical activity choices. Peers and other social factors have also been shown to heavily influence the diet choices of adolescents in from HICs such as the USA (50).

\section{Strengths and limitations}

Previous reviews have focussed on the synthesis and analysis of quantitative data, the feasibility or effectiveness of interventions (51), and data that has been collected in high income countries.(52) The current review is to our knowledge the first to summarise qualitative research using data from adolescents in LMICs. However, studies from only five countries were searched for in line with the focus of the TALENT consortium, and future reviews may benefit from including other LMIC countries. Finally, articles written in English were included in this review as there were no resources available to allow inclusion of articles written in other languages. Many African countries are French speaking, including Côte d'Ivoire, and some studies may have therefore been excluded. 


\section{Implications for public health interventions and future research}

Qualitative research exploring the diet and physical activity behaviours of adolescents living in the five TALENT countries is in its infancy. Six of the twelve included studies were carried out with adolescent girls, many of which focussed on the way in which body image influences adolescent diet and physical activity. However, findings from the synthesis of all the included papers highlight that fact that adolescent diet and physical activity behaviours are influenced by a multitude of complex factors including social, cultural, environmental and economic. Prioritising understanding of adolescent nutritional status in both girls and boys, as well as promoting healthy attitudes and behaviours around diet and physical activity in this population, are critical to improving the intergenerational transmission of health and wellbeing.(5) Therefore, there is a need for future research to describe the complex nature of the diet and physical activity behaviours of adolescents living in LMICs at different stages of transition. The qualitative studies included in this special issue aim to address this need.

\section{Conclusion}

The findings of this review are based heavily on research conducted in two countries, South Africa and India. These findings suggest that body image is a key factor in adolescents' (particularly girls') diet choices and engagement in physical activity even in LMICs. This was driven by a desire to look aesthetically pleasing by creating a body that was either 'thin' or 'curvy'. In some cases, the desire to look a certain way led to the uptake of dysfunctional eating practices. Other social and environmental influences included perceived safety of outdoor spaces to exercise in, academic pressures, and eating as a social activity. Food insecurity, lack of availability and affordability was a key influence on the diet choices of adolescents in Ethiopia. In-depth research exploring adolescent perceptions of diet and physical activity is needed to better understand how both boys and girls, at different stages of adolescence perceive health, diet and physical activity. More research with young people is required especially in countries where little exists to cover a wider range of issues that play a role in diet and physical activity. 


\section{References}

1. Sawyer SM, Afifi RA, Bearinger LH, et al. Adolescence: a foundation for future health. The Lancet. 2012;379(9826):1630-40.

2. Blakemore S-J. Adolescence and mental health. The Lancet. 2019;393(10185):2030-

1.

3. Popkin BM, Adair LS, Ng SW. Global nutrition transition and the pandemic of obesity in developing countries. Nutrition reviews. 2012;70(1):3-21.

4. Patton GC, Sawyer SM, Santelli JS, et al. Our future: a Lancet commission on adolescent health and wellbeing. The Lancet. 2016;387(10036):2423-78.

5. Patton GC, Olsson CA, Skirbekk V, et al. Adolescence and the next generation. Nature. 2018;554(7693):458-66.

6. Viner RM, Ozer EM, Denny S, et al. Adolescence and the social determinants of health. The Lancet. 2012;379(9826):1641-52.

7. Morrow V. Politics and economics in global questions about childhood and youth... the trouble with numbers. Sage Publications Sage UK: London, England; 2012.

8. Morrow V, Crivello G. What is the value of qualitative longitudinal research with children and young people for international development? International Journal of Social Research Methodology. 2015;18(3):267-80.

9. Malterud K. Qualitative research: standards, challenges, and guidelines. The Lancet. 2001;358(9280):483-8.

10. Bohren MA, Hunter EC, Munthe-Kaas HM, et al. Facilitators and barriers to facilitybased delivery in low-and middle-income countries: a qualitative evidence synthesis. Reproductive health. 2014;11(1):71.

11. Santos CMdC, Pimenta CAdM, Nobre MRC. The PICO strategy for the research question construction and evidence search. Revista latino-americana de enfermagem. 2007;15(3):508-11.

12. Barnett I, Ariana P, Petrou S, et al. Cohort profile: the Young Lives study. International journal of epidemiology. 2013;42(3):701-8.

13. Moher D, Liberati A, Tetzlaff J, et al. Preferred reporting items for systematic reviews and meta-analyses: the PRISMA statement. Int J Surg. 2010;8(5):336-41.

14. Unit P. Critical Appraisal Skills Programme (CASP). 10 questions to help you make sense of reviews. Oxford: Public Health Resource Unit; 2006. 
15. Reviews Cf, Dissemination. CRD's guidance for undertaking reviews in healthcare: York Publ. Services; 2009.

16. Tong A, Flemming K, McInnes E, et al. Enhancing transparency in reporting the synthesis of qualitative research: ENTREQ. BMC medical research methodology. 2012;12(1):181.

17. Braun V, Clarke V. Using thematic analysis in psychology. Qualitative research in psychology. Qualitative Research in Psychology. 2006;3(2):77-101.

18. Thomas J, Harden A. Methods for the thematic synthesis of qualitative research in systematic reviews. BMC medical research methodology. 2008;8(1):45.

19. Voorend CG, Norris SA, Griffiths PL, et al. 'We eat together; today she buys, tomorrow I will buy the food': adolescent best friends' food choices and dietary practices in Soweto, South Africa. Public health nutrition. 2013;16(3):559-67.

20. Morris P, Szabo C. Meanings of thinness and dysfunctional eating in black South African females: a qualitative study. African journal of psychiatry. 2013;16(5):338-42.

21. Sedibe HM, Kahn K, Edin K, et al. Qualitative study exploring healthy eating practices and physical activity among adolescent girls in rural South Africa. BMC pediatrics. 2014;14(1):211.

22. Kinsman J, Norris SA, Kahn K, et al. A model for promoting physical activity among rural South African adolescent girls. Global health action. 2015;8(1):28790.

23. Tshililo R, Netshikweta LM, Tshitangano GT, et al. Factors influencing weight control practices amongst the adolescent girls in Vhembe District of Limpopo Province, South Africa. African journal of primary health care \& family medicine. 2016;8(2).

24. Ahanonu EL, Jooste K. Adolescents' Interpretation of the Concept of Wellness: A Qualitative Study. Journal of caring sciences. 2016;5(4):337.

25. Gavaravarapu SRM, Vemula SR, Rao P, et al. Focus group studies on food safety knowledge, perceptions, and practices of school-going adolescent girls in South India. Journal of nutrition education and behavior. 2009;41(5):340-6.

26. Correa N, Rajaraman D, Swaminathan S, et al. Perceptions of healthy eating amongst Indian adolescents in India and Canada. Appetite. 2017;116:471-9.

27. Satija A, Khandpur N, Satija S, et al. Physical Activity Among Adolescents in India: A Qualitative Study of Barriers and Enablers. Health education \& behavior. 2018;45(6):92634 
28. Mmari K, Blum R, Sonenstein F, et al. Adolescents' perceptions of health from disadvantaged urban communities: findings from the WAVE study. Social science \& medicine. 2014;104:124-32.

29. Morrow V, Tafere Y, Chuta N, et al. "I started working because I was hungry": The consequences of food insecurity for children's well-being in rural Ethiopia. Social Science \& Medicine. 2017;182:1-9.

30. Gatti, E., Ionio, C., Traficante, D., \& Confalonieri, E. (2014). "I Like My Body; Therefore, I Like Myself': How Body Image Influences Self-Esteem-A Cross-Sectional Study on Italian Adolescents. Europe's Journal of Psychology, 10(2), 301-317. doi:10.5964/ejop.v10i2.703

31. Mooney, E., Farley, H., \& Strugnell, C. (2009). A qualitative investigation into the opinions of adolescent females regarding their body image concerns and dieting practices in the Republic of Ireland (ROI). Appetite, 52(2), 485-491. doi:https://doi.org/10.1016/j.appet.2008.12.012

32. Jiang B, Mak CN, Zhong H, Larsen L, Webster CJ. From broken windows to perceived routine activities: Examining impacts of environmental interventions on perceived safety of urban alleys. Frontiers in psychology. 2018 Dec 4;9:2450.

33. Jiang B, Mak CN, Zhong H, Larsen L, Webster CJ. From broken windows to perceived routine activities: Examining impacts of environmental interventions on perceived safety of urban alleys. Frontiers in psychology. 2018 Dec 4;9:2450.

34. Locke C, Lloyd-Sherlock P. Qualitative life course methodologies: Critical reflections from development studies. Development and change. 2011;42(5):1131-52.

35 Hulme D. Thinking 'small'and the understanding of poverty: Maymana and Mofizul's story. Journal of Human Development. 2004;5(2):161-76.

36. Caradas AA, Lambert EV, Charlton KE. An ethnic comparison of eating attitudes and associated body image concerns in adolescent South African schoolgirls. Journal of Human Nutrition and Dietetics. 2001;14(2):111-20.

37. Wrottesley SV, Pedro TM, Fall CH, et al. A review of adolescent nutrition in South Africa: transforming adolescent lives through nutrition initiative. South African Journal of Clinical Nutrition. 2019:1-39.

38. Szabo CP, Allwood CW. Body figure preference in South African adolescent females: a cross cultural study. African health sciences. 2006;6(4). 
39. Pedro TM, Micklesfield LK, Kahn K, et al. Body image satisfaction, eating attitudes and perceptions of female body silhouettes in rural South African adolescents. PLoS One. 2016;11(5).

40. Gitau TM, Micklesfield LK, Pettifor JM, et al. Eating attitudes, body image satisfaction and self-esteem of South African Black and White male adolescents and their perception of female body silhouettes. Journal of Child \& Adolescent Mental Health. 2014;26(3):193-205.

41. Feunekes GI, de Graaf C, Meyboom S, et al. Food choice and fat intake of adolescents and adults: associations of intakes within social networks. Preventive medicine. 1998;27(5):645-56.

42. De Bourdeaudhuij I, Van Oost P. Family members' influence on decision making about food: differences in perception and relationship with healthy eating. American journal of health promotion. 1998;13(2):73-81.

43. Contento IR, Williams SS, Michela JL, et al. Understanding the food choice process of adolescents in the context of family and friends. Journal of adolescent Health. 2006;38(5):575-82.

44. Abrahams Z, Mchiza Z, Steyn NP. Diet and mortality rates in Sub-Saharan Africa: stages in the nutrition transition. BMC Public Health. 2011;11(1):801.

45. Misra A, Singhal N, Sivakumar B, et al. Nutrition transition in India: Secular trends in dietary intake and their relationship to diet-related non-communicable diseases. Journal of diabetes. 2011;3(4):278-92.

46. Monteiro CA, Cannon G, Moubarac J-C, et al. The UN Decade of Nutrition, the NOVA food classification and the trouble with ultra-processing. Public health nutrition. 2018;21(1):5-17.

47. Siddiqui MZ, Donato R, Jumrani J. Looking past the Indian calorie debate: What is happening to nutrition transition in India. The Journal of Development Studies. 2019;55(11):2440-59.

48. Sciences IIfP, ICF. National family health survey (NFHS-4), 2015-16: India. Int Inst Popul Sci ICF. 2017:1-192.

49. Wentzel-Viljoen E, Lee S, Laubscher R, et al. Accelerated nutrition transition in the North West Province of South Africa: results from the Prospective Urban and Rural Epidemiology (PURE-NWP-SA) cohort study, 2005 to 2010. Public health nutrition. 2018;21(14):2630-41. 
50. Chung SJ, Ersig AL, McCarthy AM. The influence of peers on diet and exercise among adolescents: a systematic review. Journal of pediatric nursing. 2017;36:44-56.

51. Caraher M, Wu M, Seeley A. Should we teach cooking in schools? A systematic review of the literature of school-based cooking interventions. Journal of the Home Economics Institute of Australia. 2010;17(1):10-8.

52. Shepherd J, Harden A, Rees R, et al. Young people and healthy eating: a systematic review of research on barriers and facilitators. Health education research. 2006;21(2):239-57. 
Table 1. Search Terms used to identify relevant studies exploring the influences on adolescent diet and physical activity.

\begin{tabular}{|c|c|}
\hline \multirow[t]{2}{*}{ Population } & $\begin{array}{l}\text { adolescent OR adolescents OR adolescence OR youth OR young } \\
\text { OR teen OR teens OR teenager OR teenagers OR student OR } \\
\text { students OR girl OR girls OR boy OR boys OR pupil OR pupils } \\
\text { OR pubert* }\end{array}$ \\
\hline & AND \\
\hline \multirow[t]{2}{*}{ Context (location) } & $\begin{array}{l}\text { India OR South Africa OR SA OR Ethiopia OR Ivory Coast OR } \\
\text { Cote D'Ivoire OR The Gambia }\end{array}$ \\
\hline & AND \\
\hline \multirow[t]{2}{*}{ Context (study design) } & $\begin{array}{l}\text { Qualitative* OR mixed methods OR Interview* OR focus group* } \\
\text { OR diary OR ethnograph* OR } 24 \text { hour recall OR food diary OR } \\
\text { observation* OR experience* }\end{array}$ \\
\hline & AND \\
\hline Outcome & $\begin{array}{l}\text { intake OR consumption OR food* OR diet* OR nutrition OR } \\
\text { diet* behavior* OR eating habit* OR eating* OR practices OR } \\
\text { healthy eating* OR physical activity* OR PA OR exercise* OR } \\
\text { Sedentary Behaviour }\end{array}$ \\
\hline
\end{tabular}


Table 2. Characteristics of Included Studies

\begin{tabular}{|c|c|c|c|c|c|c|c|}
\hline $\begin{array}{l}\text { First } \\
\text { Author, year }\end{array}$ & Main objective(s) & Study Design & $\begin{array}{l}\text { Number of } \\
\text { adolescents }\end{array}$ & Age & Gender & Country & $\begin{array}{l}\text { Contex } \\
\text { t }\end{array}$ \\
\hline $\begin{array}{l}\text { Morris, } 2013 \\
20\end{array}$ & $\begin{array}{l}\text { To explore the meaning } \\
\text { of 'thinness' and } \\
\text { dysfunctional eating } \\
\text { among black adolescent } \\
\text { girls living in Soweto. }\end{array}$ & FGDs & 40 & $\begin{array}{l}\text { Age range: } \\
14-18\end{array}$ & Girls & $\begin{array}{l}\text { South } \\
\text { Africa }\end{array}$ & Urban \\
\hline $\begin{array}{l}\text { Sedibe, } 2014 \\
21\end{array}$ & $\begin{array}{l}\text { To explore factors } \\
\text { associated with healthy } \\
\text { eating behaviours and } \\
\text { physical activity among } \\
\text { adolescent girls. }\end{array}$ & $\begin{array}{l}\text { In-depth, duo } \\
\text { interviews }\end{array}$ & $\begin{array}{l}22 \text { (11 friend } \\
\text { pairs) }\end{array}$ & $\begin{array}{l}\text { Age range: } \\
16-19\end{array}$ & Girls & $\begin{array}{l}\text { South } \\
\text { Africa }\end{array}$ & Rural \\
\hline
\end{tabular}


Accepted manuscript

\begin{tabular}{|c|c|c|c|c|c|c|c|}
\hline $\begin{array}{l}\text { Kinsman, } \\
2015 \\
22\end{array}$ & $\begin{array}{l}\text { To identify the facilitators } \\
\text { and barriers to physical } \\
\text { activity among adolescent } \\
\text { girls. }\end{array}$ & FGDs & 51 & $\begin{array}{l}\text { Age range: } \\
13-19\end{array}$ & Girls & $\begin{array}{l}\text { South } \\
\text { Africa }\end{array}$ & Rural \\
\hline $\begin{array}{l}\text { Ahanonu, } \\
2016 \\
24\end{array}$ & $\begin{array}{l}\text { To explore adolescents' } \\
\text { interpretation of wellness. }\end{array}$ & FGDs & 58 & $\begin{array}{l}\text { Mean age: } \\
16.6\end{array}$ & Mixed & India & $\begin{array}{l}\text { Not } \\
\text { reporte } \\
\text { d }\end{array}$ \\
\hline $\begin{array}{l}\text { Tshililo, } \\
2016 \\
23\end{array}$ & $\begin{array}{l}\text { To explore factors related } \\
\text { to weight control } \\
\text { practices among } \\
\text { adolescent girls. }\end{array}$ & $\begin{array}{l}\text { Individual, in-depth } \\
\text { interviews. }\end{array}$ & 30 & $\begin{array}{l}\text { Age range: } \\
13-19\end{array}$ & Girls & $\begin{array}{l}\text { South } \\
\text { Africa }\end{array}$ & $\begin{array}{l}\text { Not } \\
\text { reporte } \\
\text { d }\end{array}$ \\
\hline $\begin{array}{l}\text { Gavaravarap } \\
\text { u, } 2008 \\
25\end{array}$ & $\begin{array}{l}\text { To explore food safety } \\
\text { knowledge, perceptions, } \\
\text { and practices of } \\
\text { adolescent girls. }\end{array}$ & FGDs & $\begin{array}{l}\text { Sample size not } \\
\text { reported. } 32 \\
\text { FGDs }\end{array}$ & $\begin{array}{l}\text { Age range: } \\
10-19\end{array}$ & Girls & India & Mix \\
\hline Mmari, 2014 & To explore adolescents' & Community mapping, & 119 adolescents & Age range: & Mixed & South & Urban \\
\hline
\end{tabular}


Accepted manuscript

\begin{tabular}{|c|c|c|c|c|c|c|c|}
\hline 28 & $\begin{array}{l}\text { perceptions of health and } \\
\text { health challenges. }\end{array}$ & $\begin{array}{l}\text { Photovoice, Individual } \\
\text { interviews and Focus } \\
\text { Group Discussions. }\end{array}$ & $\begin{array}{l}\text { from India. } \\
88 \text { adolescents } \\
\text { from South } \\
\text { Africa. }\end{array}$ & $15-19$ & & $\begin{array}{l}\text { Africa and } \\
\text { India }\end{array}$ & \\
\hline $\begin{array}{l}\text { Satija, } 2018 \\
27\end{array}$ & $\begin{array}{l}\text { To explore barriers and } \\
\text { facilitators of physical } \\
\text { activity among school } \\
\text { children in New Delhi. }\end{array}$ & FGDs & 174 & $\begin{array}{l}\text { Age range: } \\
12-16\end{array}$ & Mixed & India & $\begin{array}{l}\text { Not } \\
\text { reporte } \\
\text { d. }\end{array}$ \\
\hline $\begin{array}{l}\text { Morrow, } \\
2017\end{array}$ & $\begin{array}{l}\text { To explore how food } \\
\text { insecurity affects children }\end{array}$ & Case studies & $\begin{array}{l}8 \text { studied } \\
\text { longitudinally }\end{array}$ & $\begin{array}{l}\text { Information } \\
\text { from }\end{array}$ & Mixed & Ethiopia & Rural \\
\hline
\end{tabular}


Accepted manuscript

\begin{tabular}{|c|c|c|c|c|c|c|c|}
\hline 29 & over time. & & $\begin{array}{l}\text { across } 4 \text { time } \\
\text { points (2007, } \\
2008,2011 \text { and } \\
2014) .\end{array}$ & $\begin{array}{l}\text { adolescents } \\
\text { aged 12-19 } \\
\text { used in this } \\
\text { review only. }\end{array}$ & & & \\
\hline $\begin{array}{l}\text { Gavaravarap } \\
\text { u, } 2015 \\
25\end{array}$ & $\begin{array}{l}\text { To explore the } \\
\text { differences in risk } \\
\text { perceptions of } \\
\text { overweight/obese and } \\
\text { normal-weight } \\
\text { adolescents about obesity } \\
\text { and associated risk } \\
\text { factors. }\end{array}$ & FGDs & $\begin{array}{l}79 \\
\text { With both } \\
\text { overweight/obese } \\
\text { and healthy- } \\
\text { weight } \\
\text { adolescents. }\end{array}$ & $11-14$ years & Mixed & India & $\begin{array}{l}\text { Not } \\
\text { reporte } \\
\text { d }\end{array}$ \\
\hline
\end{tabular}


Table 3. A Table to Indicate which Themes were Discussed by Adolescents in Each Country

Themes and sub-themes relevant to each site

\begin{tabular}{|c|c|c|c|c|}
\hline \multirow[b]{2}{*}{ Themes } & \multirow[b]{2}{*}{ Subthemes } & \\
\hline & & South Africa & India & Ethiopia \\
\hline \multirow{3}{*}{$\begin{array}{l}\text { The } \\
\text { Influence } \\
\text { of Body }\end{array}$} & Desire to be thin vs & $X$ & & $X$ \\
\hline & 'curvy' & & & \\
\hline & & $\mathbf{Y}$ & & \\
\hline \multirow{2}{*}{$\begin{array}{l}\text { Image and } \\
\text { Self- }\end{array}$} & & $\boldsymbol{\Lambda}$ & & \\
\hline & influencing body image & & & \\
\hline \multirow{3}{*}{$\begin{array}{l}\text { Esteem on } \\
\text { Diet and } \\
\text { Physical }\end{array}$} & Dysfunctional eating & $X$ & & \\
\hline & practices & & & \\
\hline & & & & \\
\hline \multicolumn{5}{|l|}{ Activity } \\
\hline \multirow{9}{*}{$\begin{array}{l}\text { Social and } \\
\text { Environme } \\
\text { ntal } \\
\text { Influences } \\
\text { on Diet and } \\
\text { Physical } \\
\text { Activity }\end{array}$} & Safety of outside & & & \\
\hline & spaces and physical & & & \\
\hline & activity & & & \\
\hline & Academic nrescure & $X$ & $X$ & \\
\hline & versus diet and physical & & & \\
\hline & activity & & & \\
\hline & 3 Eating and doing & $X$ & $X$ & $X$ \\
\hline & physical activity with & & & \\
\hline & friends and family & & & \\
\hline \multirow{6}{*}{$\begin{array}{l}\text { Poverty, } \\
\text { Diet, and } \\
\text { Physical } \\
\text { Activity }\end{array}$} & Food (in) security & $X$ & & $X$ \\
\hline & Food safety and & & $\mathrm{X}$ & \\
\hline & hygiene & & & \\
\hline & Poverty as a barrier and & & $X$ & $X$ \\
\hline & facilitator to physical & & & \\
\hline & activity & & & \\
\hline
\end{tabular}




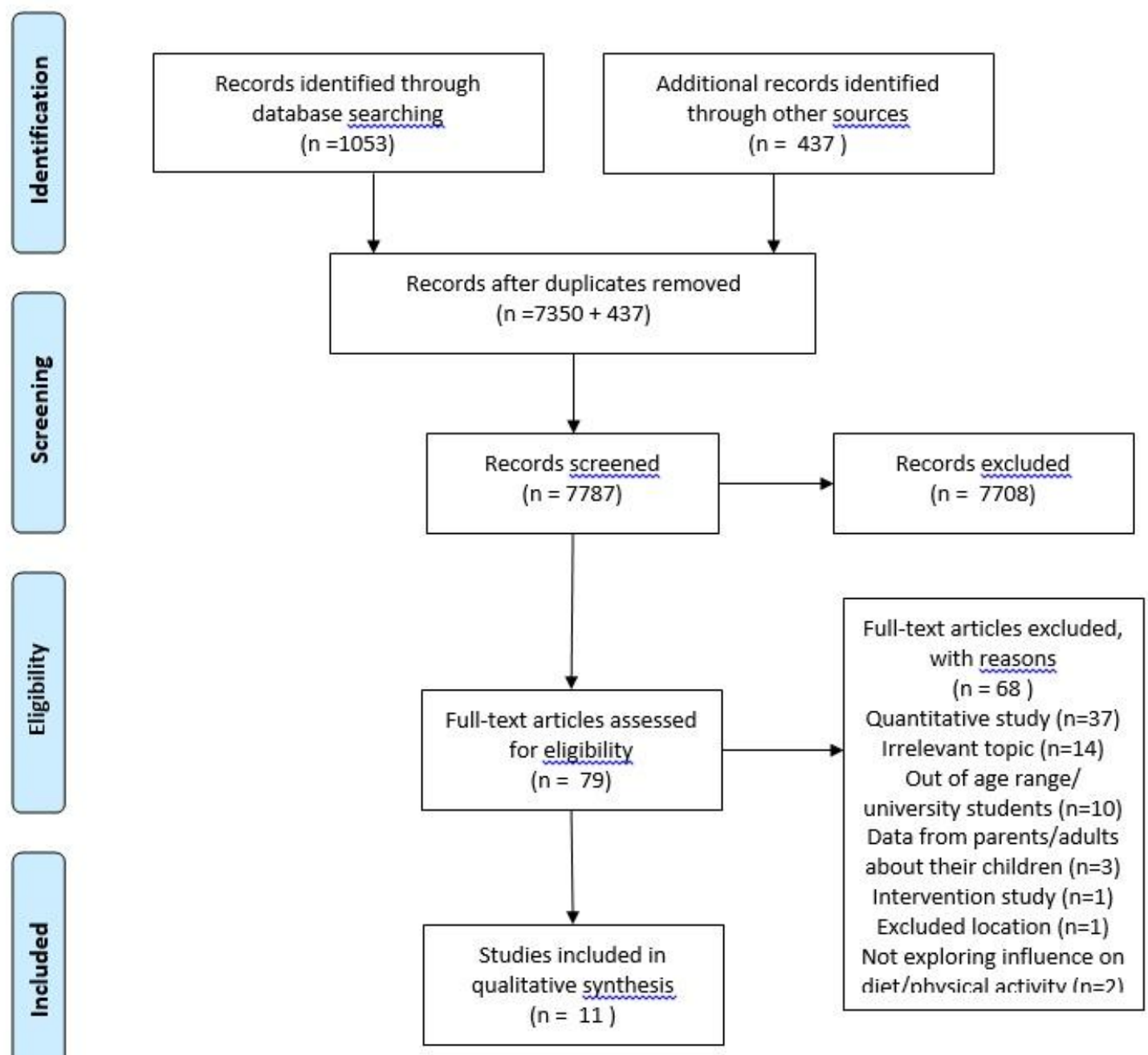

From: Moher D, Liberati A, Tetzlaff J, Altman DG, The PRISMA Group (2009). Preferred Reporting ftems for Systematic Reviews and MetaAnalyses: The PRISMA Statement. RLSS Med 6(7): e1000097. doi:10.1371/journal.pmed1000097

For more information, visit www. prisma-statement.org.

Figure 1. PRISMA Flow Diagram (13) 
Accepted manuscript

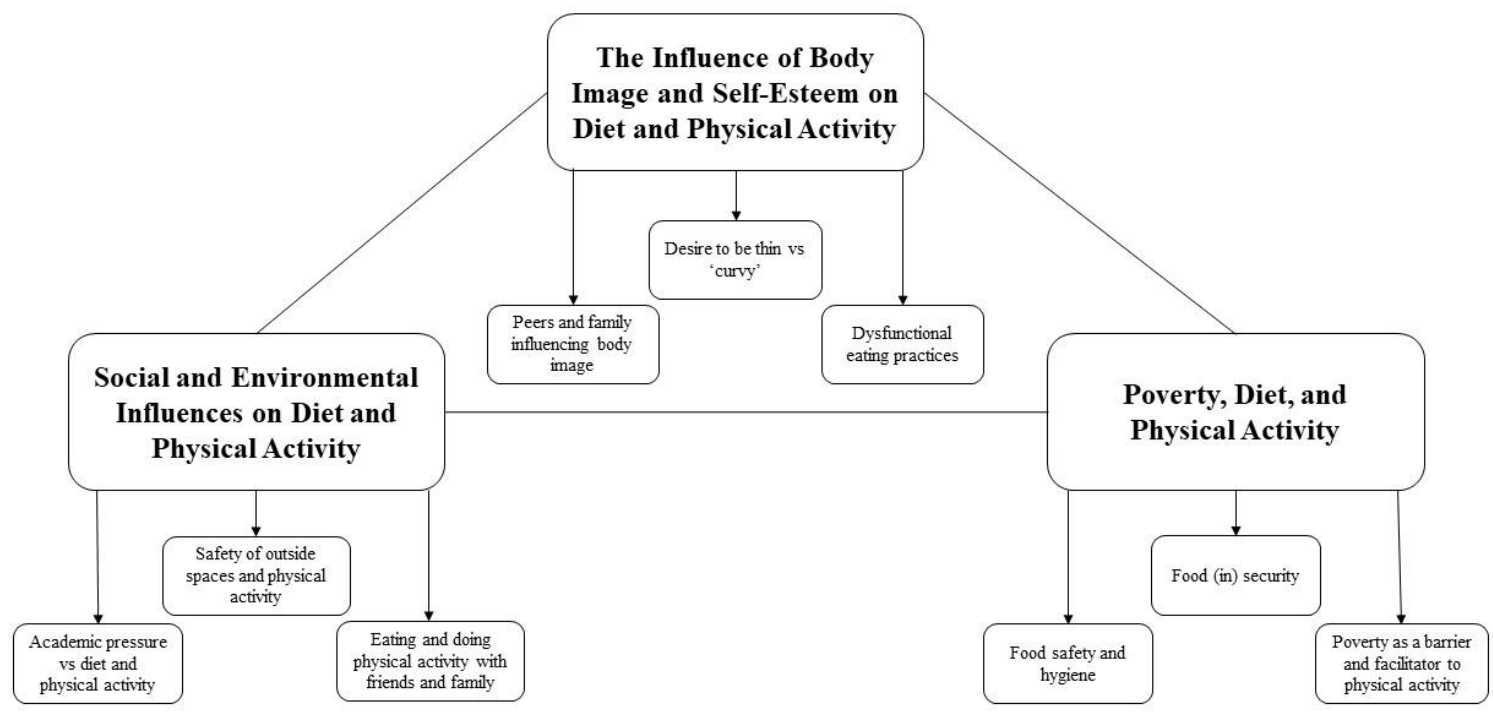

Figure 2. A Visual Display of Synthesised Findings across the Included Studies. 